\title{
GROUND PENETRATING RADAR INVESTIGATIONS OF LANDSLIDES: A CASE STUDY IN A LANDSLIDE IN RADZISZÓW
}

\author{
A. BORECKA, J. HERZIG \\ AGH University of Science and Technology, Faculty of Geology, Geophysics and Environmental Protection, \\ Department of Hydrogeology and Engineering Geology, al. Mickiewicza 30, 30-059 Kraków
}

\section{DURJASZ-RYBACKA}

EKOID, 40-236 Katowice, al. Roździeńskiego 188

\begin{abstract}
The article presents the results of research of the activated landslide in Radziszów in 2010. The study focused on the evaluation of engineering geology conditions, preceded by geophysical surveys. It mainly focused on the GPR method using the IDS georadar equipped with antennas in the frequency range of $100 \mathrm{MHz}$. Antenna selection was based on archival research which showed that the depth of occurrence of clays, where the roof can be a potential slip surface, ranges between 3-10 $\mathrm{m}$ below the surface.

GPR method applied allowed the course of the potential slip surface to be determined and the results obtained significantly correlated with the results of engineering geology tests carried out.
\end{abstract}

Key words: geophysical methods - GPR, geohazards, landslide

\section{LOCATION OF THE AREA OF RESEARCH AND MEANS TO DEVELOP THE ADJACENT AREAS}

The area in question is located in Radziszów, Skawina commune, Kraków district, the Małopolskie province. The area of research is a fragment of landslide marked by number 109 on the Map of landslides and areas at risk of slope movement in Skawina - the town and rural area. This part of the landslide is active and it occupies the space between two streets, Wytrzyszczek and Kwiatowa (Fig. 1). The Radziszów landslide is a typical example of landslides occurring along the escarpment.

The area of the land being researched is partly developed. The buildings include detached houses with outbuildings situated along two streets, Wytrzyszczek and Kwiatowa. Moreover, there is a production plant on Wytrzyszczek street. Within the borders of the study, there is a network of seven wells, reaching the depth up to $6 \mathrm{~m}$ and elements of technical infrastructure, i.e., a gas pipeline or a waterline (Fig. 2). As a result of geodynamic movements, an escarpment was formed, which clipped the southern corner of an industrial and service building, which was thus dam-
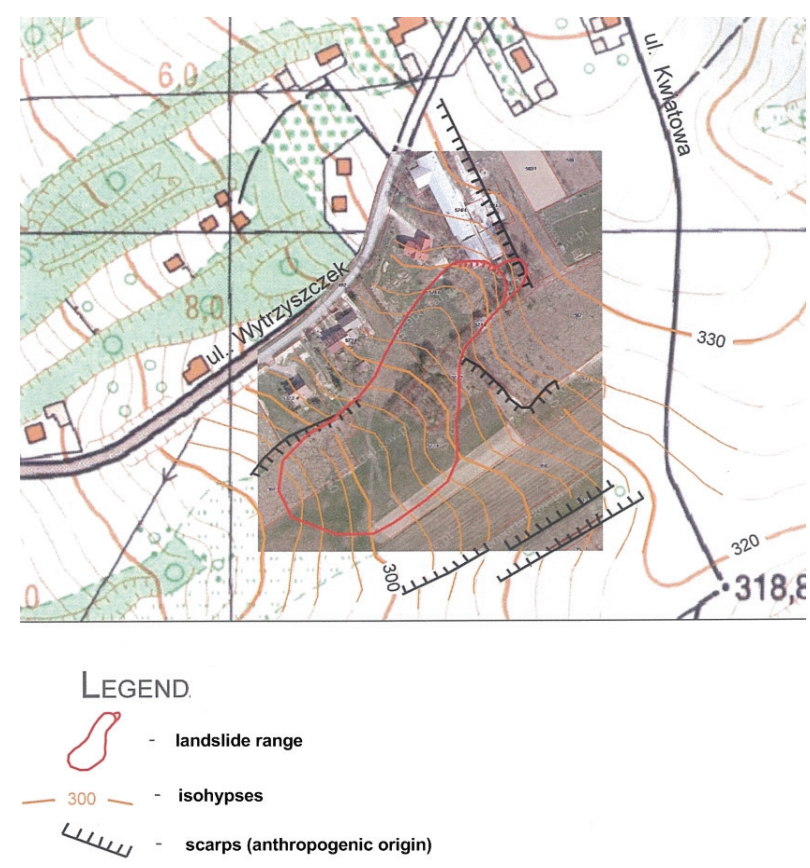

Fig. 1. Location map of the fragment of landslide in question

aged. Due to the risk of collapse, the building was pulled down, but the structure of foundation was retained. The rest of the buildings near the landslide was not damaged. At present, the industrial and service 


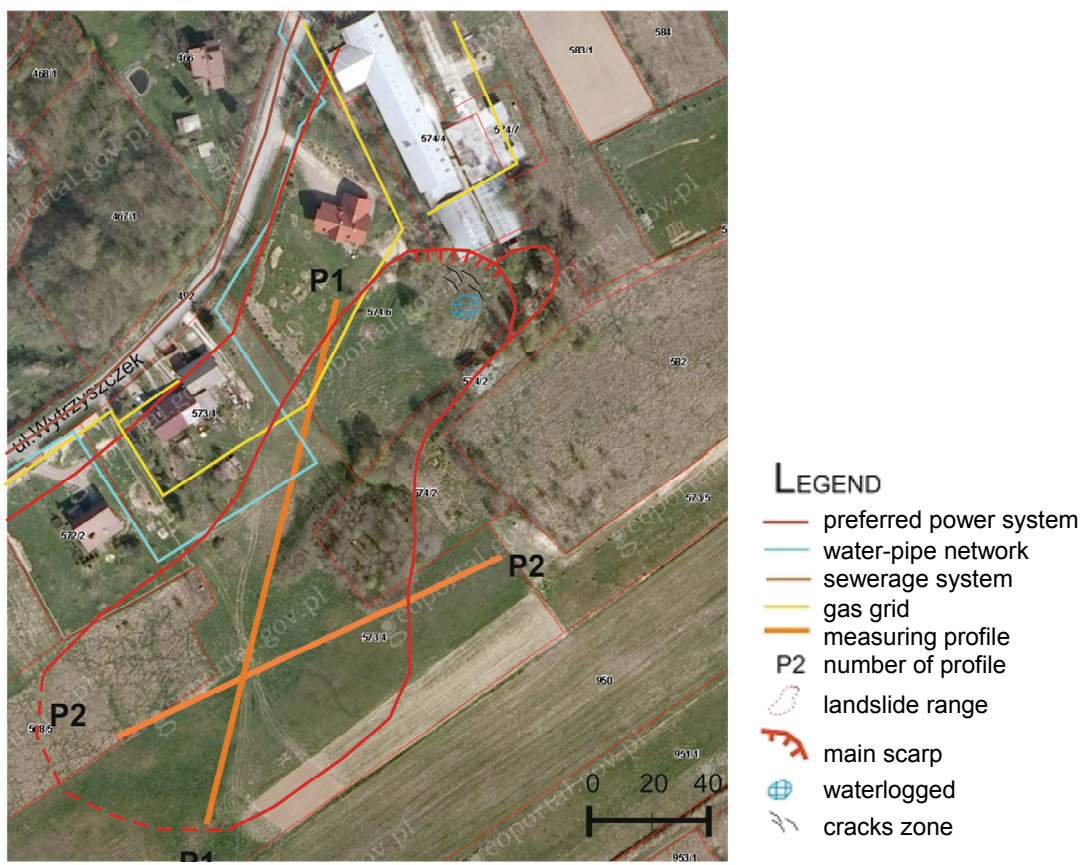

Fig. 2. Arrangement of the underground infrastructure within the borders and areas adjoining the landslide and GPR profiles

buildings, which are in the immediate proximity of the damaged building and a dwelling house below, where a drainage system has been made to remove water, are at the greatest risk.

\section{GEOLOGICAL STRUCTURE}

Near-surface deposits of the area under investigation are composed of quaternary clay minerals, silty clay, weathered sandstone and silt (loess) (Burtan [3]).

In the foreland, weathered and diluvial silty clay is more or less sandy and may contain angular rock crumbs and an admixture of loess. Their thickness amounts to 3 to 4 metres. Diluvial silty clay and weathering are still being formed. However, most of them date back to the Pleistocene.

In the area of planned geological works, there are also coulluvial clay, rock rubble, silty clay and blocks (packages of flysch). Colluvial landslides contain large amounts of silty clay, clay and sandstone and mudstone rubble, which derive from the destruction of rocks of the substratum. The deposits are characterized by a great variety of thickness (from several to a dozen or so metres), which depends on the depth and size of landslides. The material in colluvial formations is greatly diversified and layered chaotically.

Below the quaternary cover there are clay and mudstone of Skawina layers (the Neogene). Those deposits are characterized by the occurrence of fine sand fillers and in some areas, coarse-grained sand and gravel.

The first level of waters occurs in the quaternary colluvial and landslide formations. It has been confirmed by means of drilling (Różański [2]), which prove the existence of abundant water seepage at the depth of $2 \mathrm{~m} ; 3,2 \mathrm{~m}$ and $5 \mathrm{~m}$ below the ground level.

\section{RECONNAISSANCE RESEARCH BY MEANS OF GPR METHOD}

Ground Penetrating Radar, a non-invasive method of imaging the subsurface with electromagnetic waves is used to characterize the stratigraphy at potential landslide sites and to search for potential failures (Daniels [7], Moorman et al. [8], Busby et al. [5], Bichler et al. [4], Sass et al. [6], Karczewski [1]).

\section{Measurement methodology}

The measurement was conducted using the IDS georadar equipped with antennas in the frequency range of $100 \mathrm{MHz}$.

The research was carried out along two profiles located according to the line of the greatest fall of the landslide surface (Fig. 2).

In accordance with the commonly accepted rules stating that the measurements made by the GPR must be very efficient, they should be started above the main 
escarpment of the landslide and then continued along a slope and beside the largest line of fall. In the case of the landslide in Radziszów, this sort of profile arrangement would be in fact incorrect in terms of unfavourable measuring conditions in the upper part of the research area. In the area of the land lying directly below the main escarpment there appear numerous intersecting crevices and bumps, which generate multiple reflections on the echogram, resulting from the changeable and too great a distance between the antenna and the surface. It is partly covered with flora, which indicates that the soil where it grows is boggy. The water saturation of soil is associated with high muffling of a signal, which reduces the real depth range considerably. Apart from the flora characteristic of boggy areas, there are also countless shrugs and trees in the upper part of the landslide and they hinder measuring along the straight line.

The measurements along profile 1 were made twice by means of two ranges of window functions, 600 ns (echogram P1) and 800 ns (echogram P1'). The sampling 1024 with the measurement step of $20 \mathrm{~cm}$ was used in both cases.

For profile 2 (echogram P2) it has been assumed that the window function is $600 \mathrm{~ns}$, sampling step is 1024 and measurement step is $20 \mathrm{~cm}$.

\section{Interpretation of the results of research}

In accordance with a map of arrangement of the profiles (Fig. 2) profile P1 intersects with the water supply system in two places and a gas pipeline in one place. The presence of this type of infrastructure in the substratum may generate hyperbolic reflections on the echogram. A comparison of the echogram P1 with the map mentioned above has made it possible to precisely identify the reflections from the pipes channelling water. However, the reflections in the area of an intersection of the profile and gas pipeline have not been observed. The lack of distinctive reflections from the gas pipeline might be caused by the fact that it crosses the profile at a small angle, which results in a flattening of a hyperbole.

The analysis of echogram P1 before making a topographic correction indicates that the maximum measurement range of the GPR in this case is about 8 metres below the ground level (there are strong reflections visible between the 25th and 95th metre of the profile at this depth).

The authors eliminated the possibility of reflections being produced by objects on the ground surface, i.e., trees growing towards the east of the profile.

After making the topographical correction, the reflections in question change their nature noticeably, lying almost horizontally (Fig. 3). At the same time, there also appear reflections on the echogram, which might be the reflections from the explored slide surface.

The course of potential slide surfaces suggested by the author is presented in Fig. 3b. On the basis of the
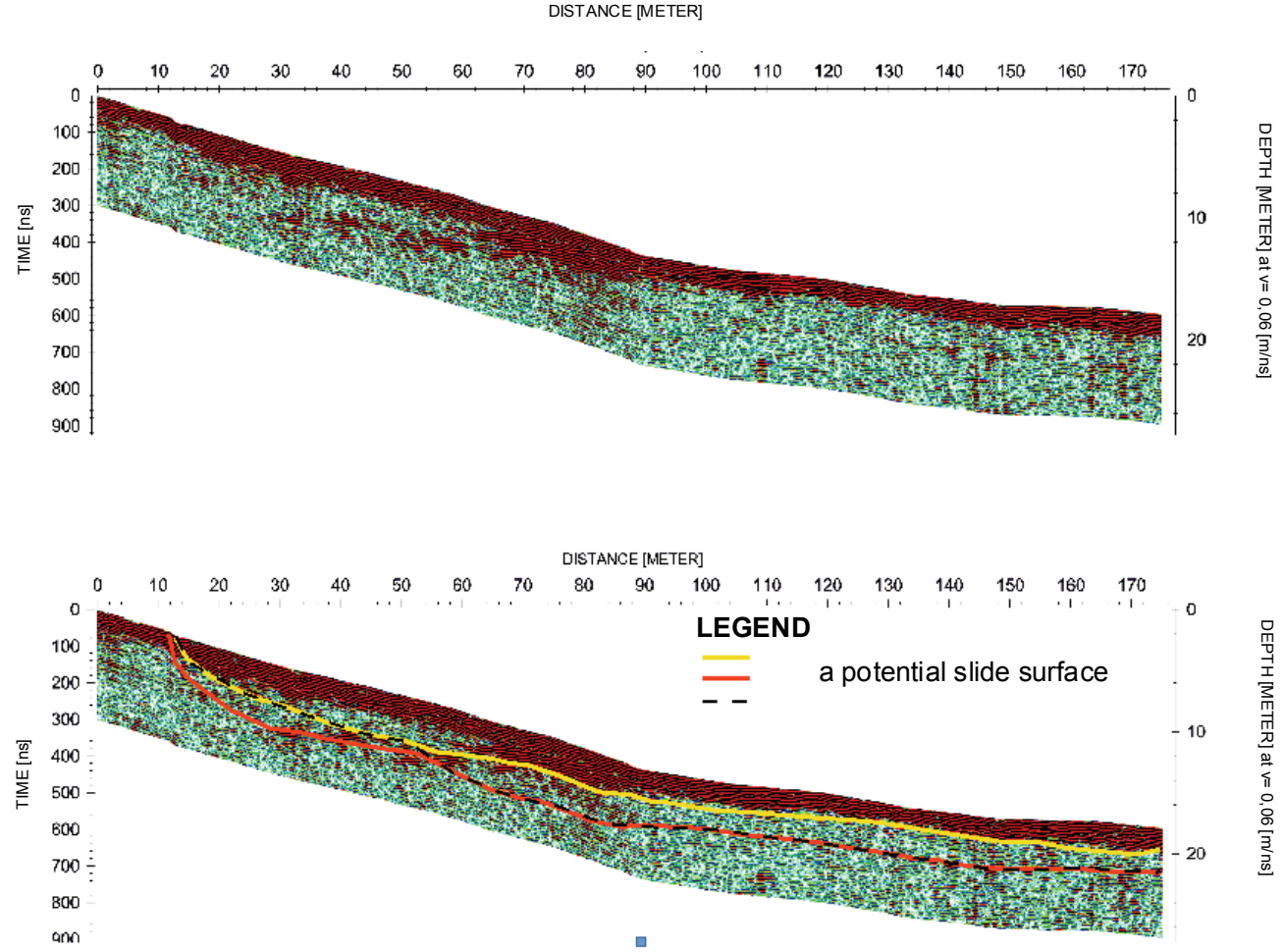

Fig. 3. Echogram P1(a) and echogram P1 with the course of slide surface marked on the graph (b) 
echogram it is not possible to determine explicitly which of the options described is closest to reality. In order to achieve this it is necessary to connect the GPR data with the lithological profiles obtained through drillings.

Grounding on the echogram analysed might suggest that there is a slide surface at the depth of 4 to 6 metres below the ground level.

In the case of echogram P2 a preliminary interpretation of the data without the correction of height difference was made, which made it possible to identify reflections generated by the objects on the ground surface. Figure 4 presents echogram P2 with hyperboles of reflections from the ground objects prepared for preliminary interpretation (zone A). In the process of creating the echogram from Fig. 4 during the timedepth conversion the speed of $0.3[\mathrm{~m} / \mathrm{ns}]$ (the speed of electromagnetic wave in air) has been used, thanks to which it is possible to determine the distance between the object and the profile and confirm the presence of the object in the research area. In the case of echogram P2 it has been established that the occurring reflections derive from the trees growing towards the west from the profile.

According to the map of arrangement of the profiles (Fig. 2), profile P2 does not cross with any elements of the underground infrastructure, which is confirmed by the fact that there are no such reflections from these objects on the echogram.

Regarding a small actual range of measurement along profile P2 there is an insignificant likelihood that the obtained image includes the explored slide surface.

It is known, on the basis of archival research, that silty clay deposits predominate in the substratum in the study area, thus the signal is muffled greatly. In spite of this fact, it cannot be excluded that the border range of measurement does not overlap the border between colluvia and natural soil.

This would indicate that only near-surface deposits are subject to slow movements and the course of slide surface is in accordance with the actual range of measurements. An example of such a slide surface is presented in Fig. 5.

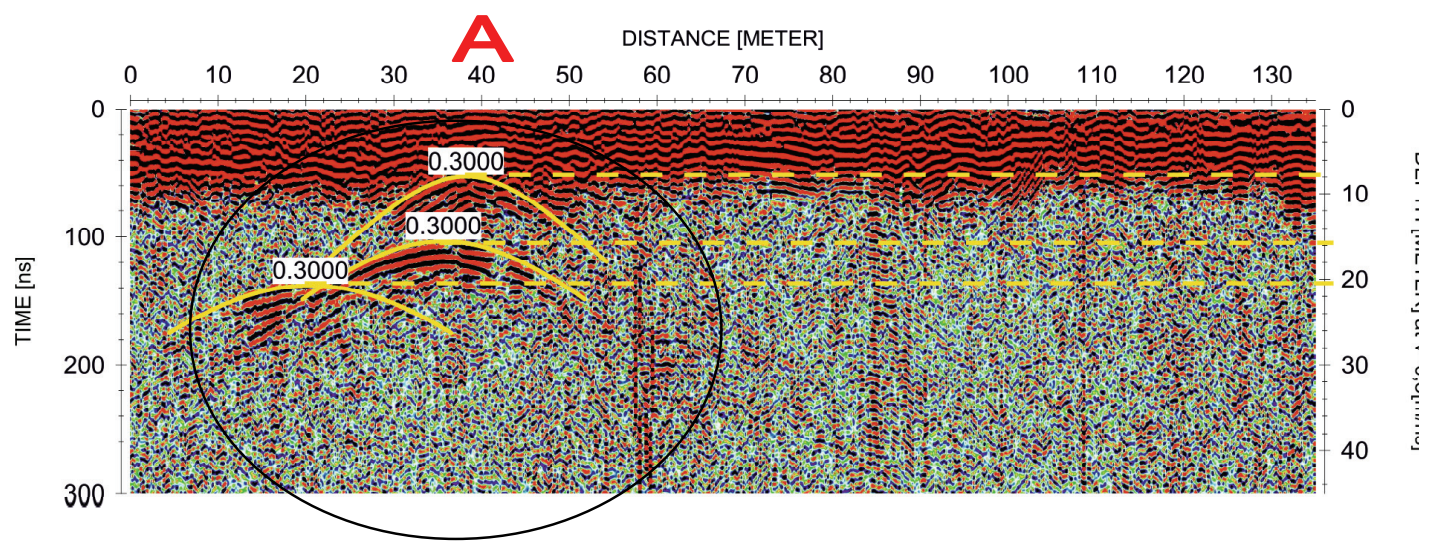

Fig. 4. Echogram P2 before introducing the procedure of gain function $(1,728 / 0,0024 / 23)$, running average and topographical correction, with the hyperboles of reflections from elements lying on the ground surface and the distance of these elements from the profile line marked

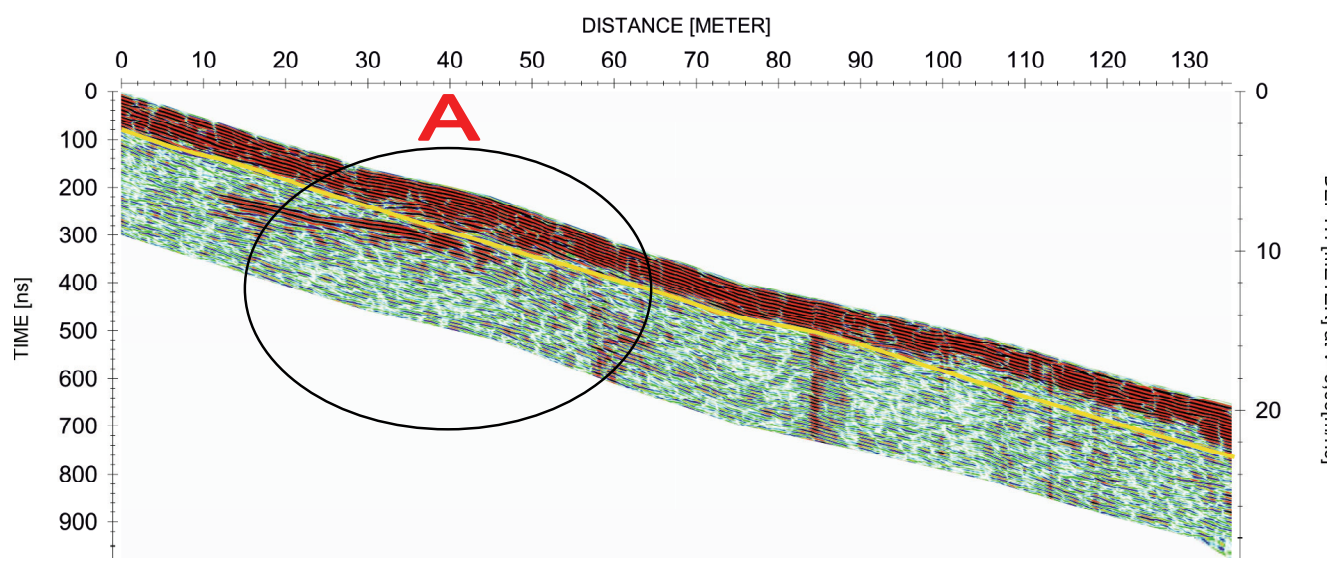

Fig. 5 Echogram P2 with a line of the maximum range considered equivalent to the slide surface 
There is also zone A marked in the graph, which corresponds to the zone of reflections from the objects on the ground surface (Fig. 4).

\section{CONCLUSIONS DRAWN FROM THE RESEARCH BY MEANS OF GPR METHOD}

In the case of the landslide in Radziszów, the GPR method allows the potential course of the slide surface to be determined only within the range of profile P1. In the case of profile $\mathrm{P} 2$, the measurement data are not clear enough to draw exact conclusions. According to Fig. 3, the maximum depth of the slide surface amounts to $5 \mathrm{~m}$. This fact is in accordance with the archival data, where a roof of clay (which might constitute the explored slide surface) lies below 2.5 metres below the ground level. Therefore, it was decided to bore at least five holes up to maximum of $5 \mathrm{~m}$ deep, the two of which were localized along the line of profile 1 and two along profile 2 . The two remaining holes were made in the upper part of the landslide, in the area of the landslide niche and above the main escarpment, where the geophysical research had not been conducted (Fig. 6).
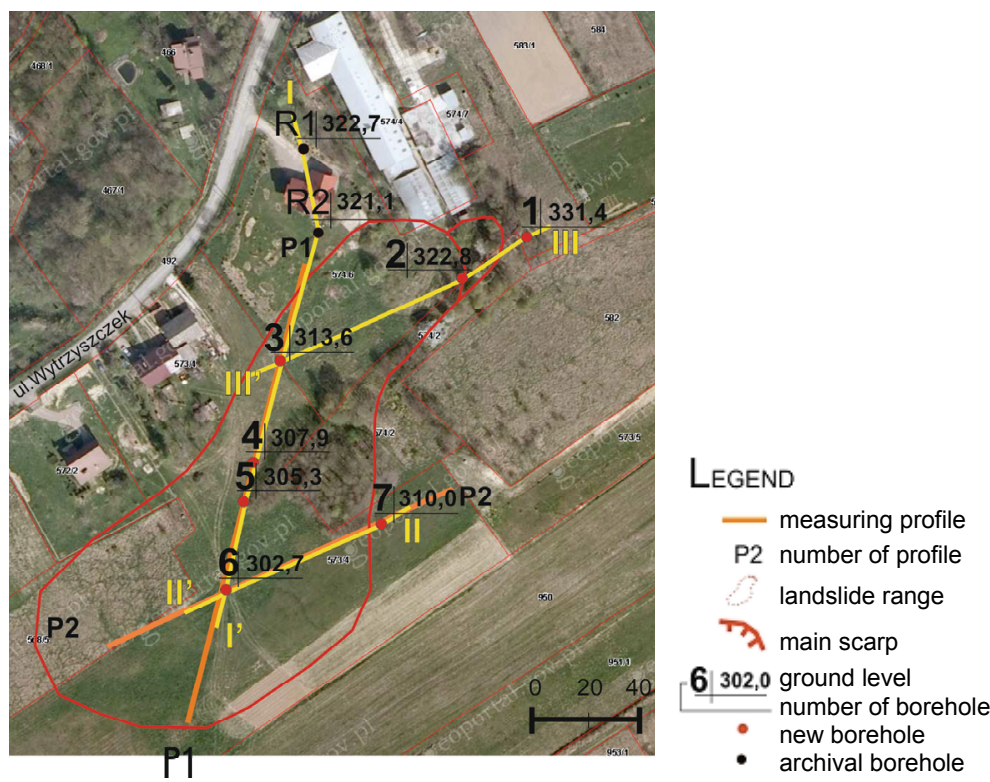

Fig. 6. The arrangement of geological bore-holes and the course of geological and engineering cross-section

Table 1. The arrangement of geotechnical parameters of the layers

\begin{tabular}{|c|c|c|c|c|c|c|}
\hline $\begin{array}{c}\text { Geotechnical } \\
\text { layer }\end{array}$ & $\begin{array}{c}\text { Soil } \\
\text { symbol }\end{array}$ & $\begin{array}{c}\text { Soil } \\
\text { consistency }\end{array}$ & $\begin{array}{c}\text { Natural } \\
\text { moisture } \\
\text { content } w_{n}[\%]\end{array}$ & $\begin{array}{c}\text { Bulk } \\
\text { density } \\
{\left[\begin{array}{l}I_{L} / I_{D} \\
{\left[\mathrm{Mg} / \mathrm{m}^{3}\right]}\end{array}\right.}\end{array}$ & $\begin{array}{c}\text { Cohesion } \\
{[\mathrm{kPa}]}\end{array}$ & $\begin{array}{c}\text { Angle of } \\
\text { friction } \\
{\left[{ }^{\circ}\right]}\end{array}$ \\
\hline $\mathrm{Ia}$ & $\pi$ & $0.35^{*}$ & $24^{*}$ & $2.00^{*}$ & 12 & $12^{*}$ \\
\hline $\mathrm{Ib}$ & $\pi$ & $0.2^{*}$ & $22^{*}$ & $2.05^{*}$ & 17 & $14^{*}$ \\
\hline $\mathrm{Ic}$ & $\mathrm{\Pi}$ & $<0.0^{*}$ & $29^{* *}$ & $2.15-2.25^{* *}$ & - & - \\
\hline $\mathrm{IIa}$ & $\mathrm{Gz}$ & $0.35^{*}$ & $24^{*}$ & $2.00^{*}$ & 12 & $12^{*}$ \\
\hline $\mathrm{Iib}$ & $\mathrm{G}$ & $0.2^{*}$ & $22^{*}$ & $2.05^{*}$ & 17 & $14^{*}$ \\
\hline $\mathrm{Iic}$ & $\mathrm{Gp}$ & $<0^{*}$ & $29^{* *}$ & $2.15-2.25^{* *}$ & - & - \\
\hline $\mathrm{III}$ & $\begin{array}{c}\mathrm{I}, \mathrm{G} \mathrm{\Pi z} / \mathrm{I}, \\
\mathrm{KWg}\end{array}$ & $0-0.15$ & 26 & $2.00^{* *}$ & 51 & 11 \\
\hline $\mathrm{IVa}$ & $\Pi, \mathrm{G}$ & $0.55^{*}$ & 26 & $1.95^{*}$ & $8^{*}$ & $9^{*}$ \\
\hline $\mathrm{IVb}$ & $\begin{array}{c}\pi, \mathrm{G} \pi+\mathrm{okr} . \\
\mathrm{p}-\mathrm{ca}, \mathrm{G} / \mathrm{P}\end{array}$ & $0.35-0.47$ & 23 & $2.05^{* *}$ & $10^{* *}$ & $11-12 * *$ \\
\hline $\mathrm{IVc}$ & $\pi, \mathrm{G} \pi, \mathrm{Gp}$ & $0.12-0.2$ & 23 & $2.05^{* *}$ & $18-20^{* *}$ & $15-16^{* *}$ \\
\hline $\mathrm{IVd}$ & $\pi, \pi \mathrm{p}$ & $\begin{array}{c}<0 \\
(-0.12)\end{array}$ & 20 & $2.15^{* *}$ & $>30^{* *}$ & $>17^{* *}$ \\
\hline $\mathrm{IVe}$ & $\mathrm{I}, \mathrm{G} \pi \mathrm{z} / \mathrm{I}$ & $0.05 / 0.2$ & $20 / 30$ & $2.11^{* *} / 1.9^{* *}$ & $51 / 37$ & $22 / 8$ \\
\hline
\end{tabular}

The parameters marked with $*$ ) have been taken from the geotechnical documentation, while those marked with ${ }^{* *}$ ) have been determined by means of method B according to PN-B-03020:1981 standard. 


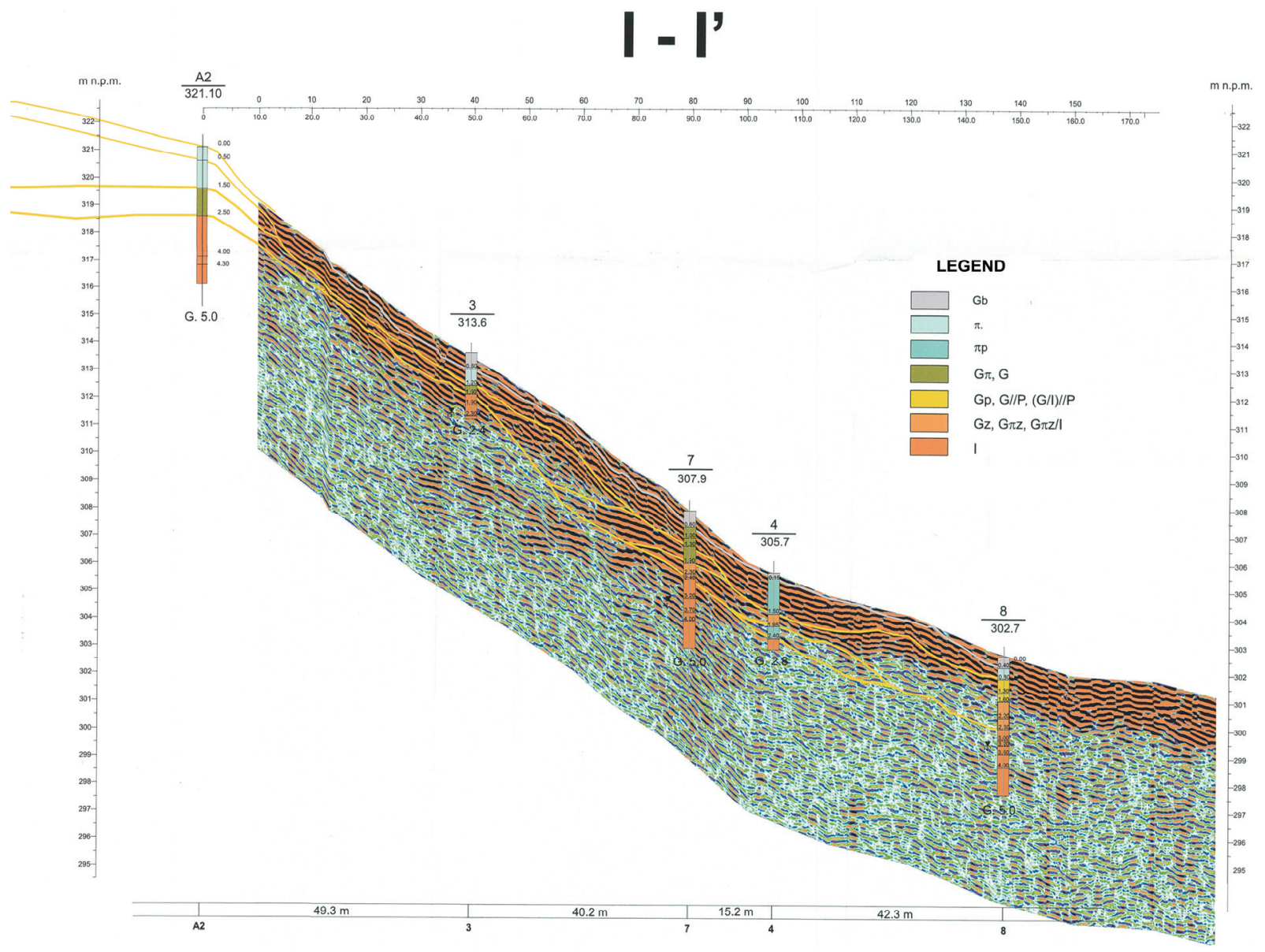

Fig. 7. The course of specific lithological layers

On the basis of the bore-holes and laboratory and archival research, the geotechnical layers have been established, as presented in Table 1.

A comparison of the data from the bore-holes with the geophysical data has made it possible to determine the arrangement of particular layers and course of the slide surface. Therefore, the lithological profiles of particular bore-holes have been marked on echograms and the terrain ordinates and the distance between particular profiles have been observed.

The analysis of profiles allowed the course of specific lithological layers to be determined (Fig. 7) and establishing the right slide surface among the versions mentioned in Fig. 3.

The greater contrast between the two centres' permittivity triggers the greater reflecting of electromagnetic waves by the surface dividing them (Karczewski [1]). Thus the reflections having the highest amplitude might occur between the layers of different lithology and moisture.

The most distinct reflections in particular profiles may be observed on the borders between:

- semi-solid silt/semi-solid clay,

- solid silty clay/semi-solid silty clay,
- semi-solid silt/plastic silty clay deposits (bore-hole no. 8),

- semi-solid silty clay/semi-solid clay.

The borders between semi-solid and solid deposits are less visible (bore-holes no. 4 and 7).

Special attention should be drawn to the fact that the actual measurement range near the bore-hole no. 8 is reduced considerably. The reflections from the border between plastic silty clay deposits and semisolid clay, lying low at the depth of 2.6 metres below the ground level, are softly marked on the echogram. It is the result of the fact that there are plastic clay deposits lying at the depth of 0.8-2.6 metres below the ground level, which are usually characterized by high muffling.

The course of potential slide surfaces has been drawn in the range of all cross-sections. The analysis of all cross-sections leads to distinguishing two main slide surfaces.

The first one has been drawn in the area of the seepage zone occurring in the layer of clay. It might be controversial to determine the seepage layer in semi-solid clay deposits. However, the clay in the range of about $10 \mathrm{~cm}$ has a specific structure. There is 


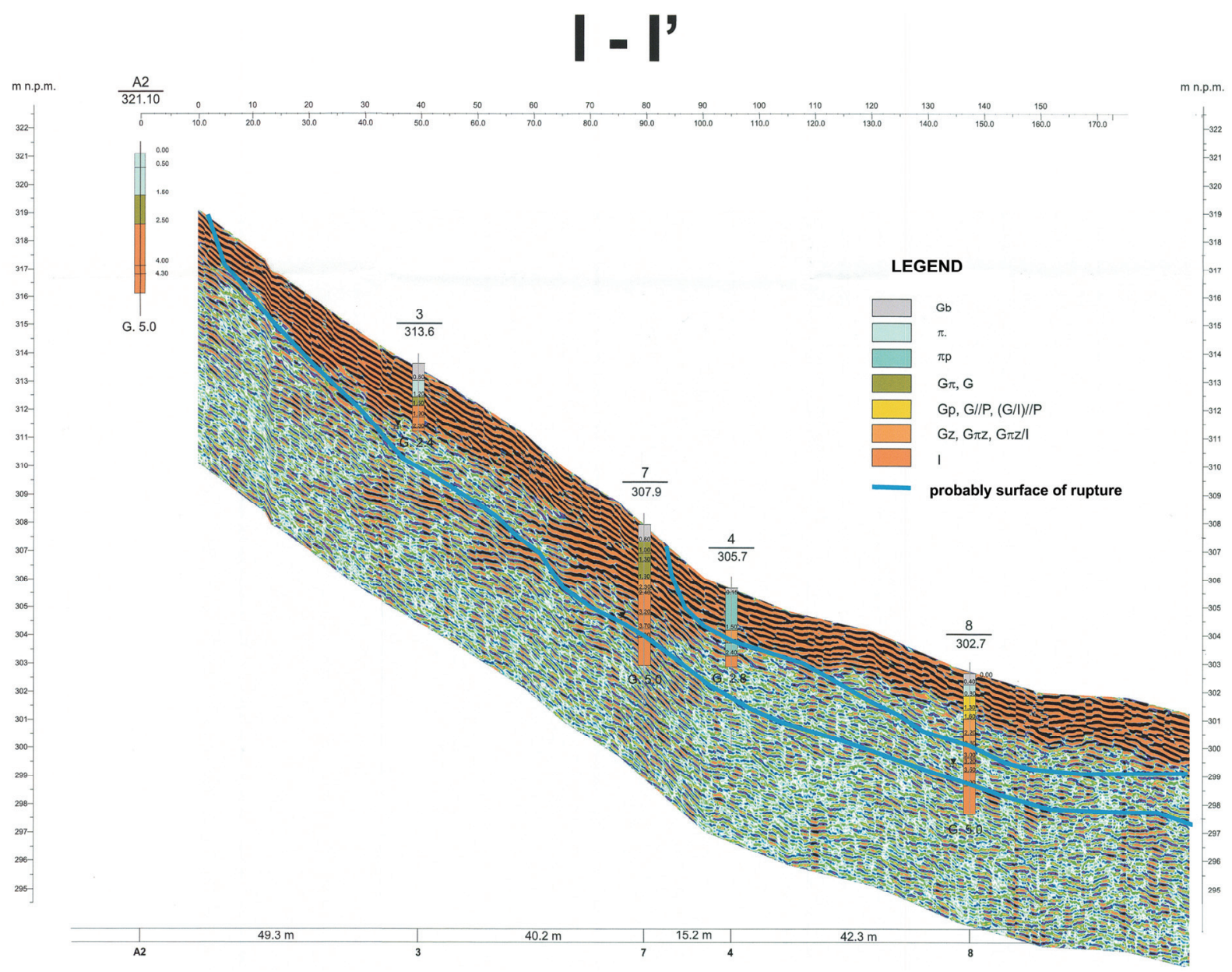

Fig. 8. Probably courses of the slide surface between particular bore-holes

a highly deformed layer that could be called "breccialike" between two layers of compacted black clay containing numerous crumbs of sandstone. According to the authors, the loose space between some of the crumbs formed out of compacted clay makes water flow possible. The thesis is confirmed by the seepage zone drilled at the depth where the layer discussed occurs. The presence of water in the crevices formed between the crumbs causes a slow increase of moisture of some fragments of clay, which in turn makes the liquidity index increase.

The lithological profile of bore-hole no. 8 indicates that there is a semi-solid layer of silt characterized by an overstated value of liquidity index $\left(I_{L}=0.2\right)$ between the semi-solid deposits $\left(I_{L}=\right.$ $0.05)$. A similar situation might be observed in bore-hole no. 3 .

In the authors' opinion, there is also the second slide surface in the range of the research area lying lower than the first one mentioned above. In the lower part of the landslide there is a layer of sandy silt characterized by quite a low plasticity limit $\left(I_{P}=6 \%\right)$. This suggests that a relatively low increase of water saturation may trigger soil liquefaction and then, consequently, landslide.

Both slide surfaces generate weak reflections on the echograms. Therefore, it is only possible to determine the course of the slide surface between particular bore-holes (Fig. 8).

\section{CONCLUSIONS}

The examples described in the paper present the usage of the GPR method in studying landslides in both favourable and unfavourable light.

On the one hand, grounding on the research of landslide in Radziszów, it may be asserted that it produces good results and it furthers the recognition of the right slide surface.

In fact, any case of landslide research by means of the GPR method should be analysed separately. The GPR method, like any geophysical method, produces the best results in favourable conditions. In the case of the GPR, these include a centre char- 
acterized by a low muffling and the lack of disturbing elements. Yet, this does not signify that satisfactory results cannot be obtained in worse conditions.

\section{REFERENCES}

[1] KARCZEWSKI J., The outline of GPR method, AGH University of Science and Technology Press, AGH-UST, Kraków 2011, (in Polish).

[2] RÓŻAŃSKI P., Opinion on the diagnosis geotechnical conditions - in the area of Pavilion $I V$ warehouse and residential building, on plots of 574/6, 574/7 in Radziszów, 2011, (in Polish).

[3] Burtan J., Geological Map of Poland, A - with Quaternary deposits, Sheet Kraków, 1: 200 000. PIG, Warszawa 1964, (in Polish).

[4] Bichler A., Bobrowsky P., Best M., Douma M., Hunter J., CALVERT T., BuRns R., Three-dimensional mapping of a landslide using a multi-geophysical approach: the Quesnel Forks landslide, Landslides, 2004, 1(1), 29-40.
[5] Busby J.P., Cuss R.J., Raines M.G., Beamish D., Application of ground penetrating radar to geological investigations, British Geological Survey Internal Report IR/04/21.

[6] Sass O., Bell R., Glade T., Comparasion of GPR, 2Dresistivity and traditional techniques for the subsurface exploration of the Öschingen landslide, Swabian Alb (Germany), Geomorphology, 2008, 93, pp. 89-103.

[7] DANIELs D.J., Surface-Penetrating Radar, Inst. of Electrical Engineers; Radar, Sonar, Navigation and Avionics Series 6, London 1996, $300 \mathrm{pp}$.

[8] Moorman B.J., Robinson S.D., Burgess M.M., Imaging periglacial conditions with ground-penetrating radar, Permafrost and Periglacial Processes, 2003, 14, 319-329.

[9] The Municipality of Skawina „www.skawina.e-mpzp.pl”: Local Area Development Plan of Skawina.

[10] The Municipality of Skawina „www.skawina.e-mpzp.pl”: Landslide maps and landslide hazard maps in Skawina - rural area, sheet M-34-76-B-a-4.

[11] PN-EN 1997-2:2009:Eurokod 7. Geotechnical design - Part 2: Ground investigation and testing (in Polish).

[12] PKN-CEN ISO/TS 17892-10:2009 Geotechnical investigation and testing - Laboratory testing of soil - Part 10: Direct shear tests (in Polish). 